\title{
Optic Nerve Head Optical Coherence Tomography Angiography Findings in Patients with Coronavirus Disease 2019
}

Mojtaba Abrishami ( $\square$ mojtaba_abrishami@yahoo.com )

Mashhad University of Medical Sciences https://orcid.org/0000-0003-2001-7929

Ramin Daneshvar

Mashhad University of Medical Sciences

Zahra Emamverdian

Mashhad University of Medical Sciences

Naser Shoeibi

Mashhad University of Medical Sciences

Shima Sedighi

Mashhad University of Medical Sciences

Talieh Saeidi Rezvani

Ferdowsi University of Mashhad

Neda Saeedian

Mashhad University of Medical Sciences

Saeid Eslami

Mashhad University of Medical Sciences

Original research

Keywords: Severe Acute Respiratory Syndrome Corona Virus 2 (SARS-CoV-2), Coronavirus Disease 2019 (COVID-19), Optical Coherence Tomography Angiography (OCTA), optic nerve head, optic disc, radial peripapillary capillary network

Posted Date: February 12th, 2021

DOI: https://doi.org/10.21203/rs.3.rs-181445/v1

License: (c) (1) This work is licensed under a Creative Commons Attribution 4.0 International License.

Read Full License 


\section{Abstract}

Purpose: To quantify the microvasculature density of the optic nerve head $(\mathrm{ONH})$ using optical coherence tomography angiography (OCTA) analysis.in patients recovered from Coronavirus Disease 2019 (COVID19)

Methods: In a comparative cross-sectional, observational study patients recovered from COVID-19, whom diagnosis of COVID-19 was confirmed by a positive reverse transcription-polymerase chain reaction of a nasopharyngeal sample were included in this study. The. OCTA of ONH was performed at least 2 weeks after recovery from systemic COVID-19. Vascular density (VD) of the all vessels (AV) and small vessels (SV) inside the disc and radial peripapillary capillary (RPC) network density were measured in COVID-19 recovered patients and compared with similar parameters in an age-matched group of normal controls.

Results: Twenty-five COVID-19 patients and 22 age-matched normal controls were enrolled in the study and one eye per participant was evaluated. Mean whole image SV VD in the COVID-19 group (49.94 \pm 2.22) was not statistically significantly different from that in the control group (49.31 \pm 1.93 ; $p$-value= 0.308). An increase in RPC VD was found in all AV and SV VD measured, which became statistically significant in whole peripapillary SV VD, peripapillary inferior nasal SV VD, peripapillary inferior temporal SV VD, peripapillary superior nasal SV VD and grid-based AV VD inferior sector ( $p<0.05$ for all comparisons).

Conclusion: Unremarkable increase was found in $\mathrm{ONH}$ microvasculature in patients who had recovered from COVID-19. These patients may be at risk of $\mathrm{ONH}$ vascular complications.

\section{Introduction}

Severe acute respiratory syndrome coronavirus 2 (SARS-CoV-2) is a new member of the Coronaviridae family of viruses, which can cause serious life-threatening respiratory illness, severe pneumonia, ${ }^{1}$ and even multiorgan failure. ${ }^{2,3}$ Various clinical presentations and fatal consequences of the associated disease, Coronavirus Disease 2019 (COVID-19), have been reported, but scarce reports regarding ocular manifestations are available. ${ }^{4,5}$

Angiotensin-converting enzyme (ACE)-2 is considered as the main receptor for SARS-CoV- 2 infection. ${ }^{6}$ ACE2 as a member of the renin-angiotensin-aldosterone system (RAAS) is present in different cell types including type II alveolar cells in the lung, arterial and venous endothelial cells, enterocytes of the small intestine, and smooth muscle cells of arterial vasculature of most organs. ${ }^{7}$ Its homologous enzyme is ACE, which is the main effector in the RAAS and ACE2 counterbalances and regulates its activity by reducing the amount of angiotensin-II and increasing Ang (1-7). ${ }^{8}$ ACE and ACE2 have been presented in the choroid and different cell types of the retina including retinal vascular endothelial cell, photoreceptor cells, Müller cells, and ganglion cells. ${ }^{9}$ Moreover, their expression in neurons and glial cells in the CNS 
have been reported. ${ }^{10}$ Hence, it seems reasonable to expect ocular, and specifically optic nerve head $(\mathrm{ONH})$ and CNS manifestations of the SARS-CoV-2 infection.

The majority of reports on the ocular involvement in COVID-19 describe ocular surface manifestations including conjunctival congestion, chemosis, and conjunctivitis. ${ }^{10,11}$ Reports of the retinal findings are numerable. Marinho and colleagues described various retinal manifestations of COVID-19 like cotton wool spots and hemorrhages, ${ }^{12}$ but these findings were called into question. ${ }^{13}$

Optical coherence tomography angiography (OCTA) is capable of depth-resolved imaging of blood flow in different retinal layers and differentiate various vascular sizes. ${ }^{12}$ In this study, we used OCTA to evaluate the $\mathrm{ONH}$ vasculature in patients recovered from COVID-19 and compare it with a normal group.

\section{Methods}

\section{Study participants}

A cross-sectional study was conducted at the Imam Reza General Hospital, Mashhad, Iran. Nurses and physicians working at Mashhad University of Medical Sciences (MUMS) with a definite diagnosis of COVID-19, confirmed by a positive test result of a nasopharyngeal swab sample real-time, reverse transcription-polymerase chain reaction, who recovered from the systemic symptoms at least 2 weeks' prior the enrolment, were included.

Detailed ocular and systemic histories were obtained from each participant and those with a history of auto-immune disease, migraine, diabetes mellitus, current pregnancy and breastfeeding, or any history of intraocular surgery were excluded. Additional exclusion criteria included absolute spherical refractive error greater than 5 diopters and cylindrical refractive error more than 2 diopters, best-corrected visual acuity less than 20/20, and evidence of glaucoma or clinically apparent retinal disease. Those with ocular media opacity, like cataract or corneal haziness, preventing high-quality imaging or reduced OCTA scan quality (i.e. quality scan index less than $7 / 10$ ) were also excluded from the analysis.

The age-matched control groups were healthy nurses and physicians employed by the MUMS who were imaged on the same OCTA machine at the Imam Reza Hospital in 2019; this group was recruited as part of an ongoing, longitudinal cohort study, PERSIAN Organizational Cohort study in MUMS.

Complete medical systemic history regarding the patients' COVID-19 symptoms, hospitalization and disease course were recorded. Oxygen saturation at the time of examination was measured by a portable pulse oximeter.

\section{Image acquisition and analysis}

OCTA scans were performed with the AngioVue (RTVue XR Avanti, Optovue, Fremont, CA, USA; Software version 2018.0.0.14), an OCTA machine with A-scan-rate of 70,000 scans per second. Each $B$ scan line is repeated to evaluate the image decorrelation. Optic disc cubes, AngioDisc $4.5 \times 4.5 \mathrm{~mm}$ HD scan (400 lines 
$\times 400$ A-scans) protocols, were scanned in the horizontal and vertical orthogonal directions. All measurements were primarily acquired using the automated default segmentation with the preset settings for the radial peripapillary capillary (RPC) network. The 3D Projection Artifact Removal by OCT $3 \mathrm{D}$ volume set were utilized.

All images were centered on the optic disc and displayed a scan quality index of at least $7 / 10$. Images with undesirable quality or image artifact were discarded and reacquired. All images in the study, mostly segmentation accuracy, were carefully reviewed by two (MA, RD) to ensure sufficient quality and resolution and any images with artifact significant enough to interfere with vessel density analysis were also excluded. For all subjects, cases or controls, only the data of the eye with better image quality was used for analysis.

To evaluate the RPC layer, a slab between the outer limit of the retinal nerve fiber layer (RNFL) and the internal limiting membrane were used. All the images were checked for segmentation errors and manually adjusted before testing the vessel density. All vessels (AV), including both large and small vessels, and small vessels (SV) VD were evaluated separately in the RPC layer. The whole image, inside disc area, in peripapillary whole, peripapillary superior and inferior hemifields, and eight segments SV RPC VD were reported. For the evaluation of AV VD, including both large vessels and small vessels, the whole image was divided into nine (three by three) grid-based sections, and AV VD in all sections was reported separately. Moreover, the whole image, inside the disc area, in peripapillary whole, peripapillary superior and inferior hemifields AV were reported.

\section{Statistical Analysis}

The normal distribution of variables was examined using the Shapiro-Wilk test and normality plots and homogeneity of variances were ascertained by Levene's test. Based on data distribution and type, either the independent-samples t-test, paired t-tests, or Mann-Whitney $\mathrm{U}$ test were used for comparisons. Chisquare test and Fisher's exact test were used for categorical variables. The level of statistical significance was set at 0.05 . All statistical analyses were performed using the SPSS program for Windows, version 20 (IBM SPSS Statistics, IBM Corporation, Chicago, IL, USA).

\section{Ethical Considerations}

The study protocol adhered to the tenets of the Declaration of Helsinki. All participants provided written informed consent before enrollment and the ethical aspects of the study were approved by the Regional Committee on Medical Ethics at Mashhad University of Medical Sciences, Mashhad, Iran (IR.MUMS.REC.1399.104).

\section{Results}

Twenty-five recovered COVID-19 patients ( 10 females, 40\%) with a mean age of $41.5 \pm 10.5$ years and 22 healthy normal controls ( 10 females, $45.4 \%$ ) with a mean age of $36.7 \pm 7.3$ years were enrolled in the 
study. Age ( $p$-value: 0.086$)$ and gender ( $p$-value: 0.706$)$ were not significantly different between the two groups. ONH parameters like cup-disc ratio and rim area were not different between the groups. (Table 1) None of the patients or controls had other systemic comorbidity except recent COVID-19 in last six months.

All patients were symptom-free for at least 2 weeks. Past medical history was otherwise unremarkable for almost all of the patients and controls. None of the included subjects, COVID-19 cases or controls, endorsed a history of diabetes mellitus. Two COVID-19 patients had a history of grade 1 hypertension which was well controlled with medications or diet. Nine patients (36\%) had a history of hospitalization for COVID-19. $\mathrm{O}_{2}$ saturation was in the normal range (94-99\%) in these patients and was not different from non-hospitalized patients ( $p$-value: 0.513 ). The mean scan quality was $8.28 \pm 0.73$ in the COVID cases and $8.50 \pm 0.67$ in the normal controls ( $p$-value: 0.293 ).

The $4.5 \times 4.5 \mathrm{~mm}$ mean whole image SV VD $(49.94 \pm 2.22)$ in the COVID-19 group was not statistically different from that in the normal control group $(49.31 \pm 1.93)$ ( $p$-value: 0.308$)$ although it seems to be greater in the COVID-19 recovered patients (Table 2). The $4.5 \times 4.5 \mathrm{~mm}$ mean whole image AV VD in the COVID-19 cohort ( $56.44 \pm 2.29)$ was also not statistically significantly different with that in the controls (56.08 \pm 1.89$)$ ( $p$-value: 0.566$)$; however, there was a tendency for higher values in the former group (Table 3) (Figure 1).

Of note, whole peripapillary SV VD $(53.14 \pm 2.31$ vs. $51.76 \pm 1.92$; p-value: 0.032$)$, peripapillary inferior nasal SV VD (53.21 \pm 4.12 vs. $48.54 \pm 2.94$; $p$-value: $<0.001)$, peripapillary inferior temporal SV VD (59.78 \pm 3.25 vs. $56.93 \pm 3.14$; $p$-value: 0.004 ), and grid based AV VD in inferior sector (60.68 \pm 2.14 vs. $62.56 \pm$ 3.15; p-value: 0.023 ) were significantly higher in COVID-19 patients, compared with normal controls. In addition, in all other parameters, except inside disc SV VD, COVID-19 patients had higher VD in AV and SV VD, but the differences were not statistically significant. Inside disc SV VD in COVID-19 patients (45.46 \pm $6.22)$ was lower than the inside disc SV VD in the normal control group (49.43 \pm 4.96 ; $p$-value: 0.021$)$.

The difference in the mean AV VD and SV VD was not statistically significant in the hospitalized versus the non-hospitalized COVID-19 patients.

\section{Discussion}

In the present study, we used OCTA to determine the vascular density in the ONH and the RPC in a relatively young, mild involved, without other comorbidity and minority hospitalized, cohort of recovered COVID-19 patients and compare it with an age-matched normal control group. Except inside disc SV VD which was less in the COVID-19 patients, in all RPC measured SV and AV VD recovered COVID-19 patients showed higher values, which became statistically significant in whole peripapillary SV VD, peripapillary inferior nasal SV VD, peripapillary inferior temporal SV VD, and grid-based AV VD Inferior sector. In other segments of peripapillary SV VD and grid-based sectors of AV VD, vessel densities tend to be higher in the COVID group but this did not reach statistical significance. 
In an autopsy study, Casagrande and associates detected SARS-CoV-2 viral particles in the retina of patients who had deceased due to COVID-19. ${ }^{14}$ Presence of ACE2 receptors in CNS and various layers of the retina and choroid have been reported; 9,10 hence pathologic changes in the ocular tissues, and especially in $\mathrm{ONH}$ and retina, may be expected.

In a recent case series, in seven out of eight patients recovered from COVID-19, RNFL thickness was increased when compared to their available previous examinations ${ }^{15}$. The only patient with decreased RNFL thickness had glaucoma. In this case series the mean increase in RNFL thickness was very small (mean: $4.3 \mu \mathrm{m}$ ); however, it indicates probable ONH involvement in COVID-19. Moreover, Guillain-Barré syndrome and Miller-Fisher-like syndrome have also been reported in association with SARS-CoV-2 infection. ${ }^{16}$-17 In recent studies SARS-CoV-2 potential for neuroinvasion has been suggested. ${ }^{18}$ It seems that in-line with the previous reports of retinitis and optic neuritis induced by coronaviruses in animal models, ${ }^{19}$ and the proposed neuroinvasion hypothesis, SARS-CoV-2 can cause neuro-inflammation and neuro-infection in humans, too. Besides the neurologic involvements, as retinal ganglion cells, Müller cells, and blood vessels are potential targets of the virus the $\mathrm{ONH}$ and retinal findings in COVID-19 are well anticipated. Vascular changes can be either primary or secondary to alternations in the hemodynamic demands of the inflamed and damaged tissues.

OCTA analysis is an invaluable tool in the evaluation of vascular changes in the retina and $\mathrm{ONH}$ for diagnosis, staging, and monitoring in glaucoma. ${ }^{20,21}$ In addition, in several neurologic conditions, including preclinical Alzheimer's disease, OCTA was found to be helpful. ${ }^{22}$ In other neurodegenerative diseases and even mild cognitive disorders, OCTA has been proposed as an additional biomarker for the early diagnosis and disease activity monitoring. ${ }^{23,24}$ In this study, we found that $\mathrm{ONH}$ microvasculature was somewhat increased compared to the age-matched controls. In many segments, VD was numerically increased in these comparative analyses, although the differences were not statistically significant.

This study has several limitations. First, OCTA images were acquired during the recovery of the disease and not during the acute phase when the systemic condition was active. Second, longitudinal analysis of the patients was not performed. Third, we had a limited sample size, which can explain the lack of statistical significance in some comparisons. A larger-scale study with OCTA performed during the symptomatic phase of the disease, followed by repeat imaging at fixed intervals, would provide valuable information regarding both the short and long-term effects of COVID-19 on the ONH vascular system.

To the best of our knowledge, it's the first report of ONH OCTA findings in patients with a history of COVID-19. The clinical relevance of our finding is unclear, as the patients were all asymptomatic with $20 / 20$ vision at the time of this analysis. This can indicate the acute inflammatory phase of the ocular involvement and the associated vasodilation. It is noteworthy that the systemic and ocular disease phases can be unparalleled and occur at different times. Nevertheless, our findings in a relatively young group of COVID-19 confirmed patients who had no other comorbidity, and the comparison with an agematched normal control group, similarly imaged, is novel and may highlight the importance of continued 
vigilance for the detection of nervous tissue and ocular complications associated to COVID-19 as the pandemic evolves.

\section{Conclusion}

In conclusion, our study demonstrated significant ONH VD alterations in patients with a history of COVID19 and without other comorbidities, including an increase in all vessels and small vessels VD in the and in some segments of RPC. The potential involvement of the $\mathrm{ONH}$ and peripapillary microvasculature by COVID-19 warrants further study.

\section{Abbreviations}

COVID-19: Coronavirus Disease 2019

ONH: optic nerve head

OCTA: optical coherence tomography angiography

OCT: optical coherence tomography

SV: small vessels

AV: all vessels

VD: vessel density

RPC: radial peripapillary capillary

RNFL: retinal nerve fiber layer

SARS-CoV-2: severe acute respiratory syndrome coronavirus 2

ACE: angiotensin-converting enzyme

ACE2: angiotensin-converting enzyme 2

MUMS: Mashhad University of Medical Sciences

FAZ: foveal avascular zone

\section{Declarations}

Acknowledgement: We would like to thank Abbas Saberi and Hojjat Salmani at Mashhad PERSIAN Cohort Center, for their kind assistance with this research project. It is a pleasure for us to also acknowledge the kind supports of Capt. Mehdi Madadi. 
Authorship: All named authors meet the International Committee of Medical Journal Editors (ICMJE) criteria for authorship for this article, take responsibility for the integrity of the work as a whole, and have given their approval for this version to be published.

Financial Disclosure: The authors declared no potential conflicts of interest for the research, authorship, and/or publication of this article.

Financial Support: The authors would like to acknowledge the financial support of the Vice-Chancellor of Research of Mashhad University of Medical Sciences for this research project (code: 990069). The funding organization had no role in the design or conduct of this research.

Compliance with ethics guidelines: The study protocol adhered to the tenets of the Declaration of Helsinki. All participants provided written informed consent before enrollment and the ethical aspects of the study were approved by the Regional Committee on Medical Ethics at Mashhad University of Medical Sciences, Mashhad, Iran (IR.MUMS.REC.1399.104).

Data availability: The datasets generated and analyzed during the current study are available from the corresponding author on reasonable request.

\section{References}

1. Ahn DG, Shin HJ, Kim MH, et al. Current Status of Epidemiology, Diagnosis, Therapeutics, and Vaccines for Novel Coronavirus Disease 2019 (COVID-19). J Microbiol Biotechnol 2020;30(3):313324.

2. Gheblawi M, Wang K, Viveiros A, et al. Angiotensin-Converting Enzyme 2: SARS-CoV-2 Receptor and Regulator of the Renin-Angiotensin System: Celebrating the 20th Anniversary of the Discovery of ACE2. Circ Res 2020;126(10):1456-1474.

3. Huang C, Wang Y, Li X, et al. Clinical features of patients infected with 2019 novel coronavirus in Wuhan, China. Lancet 2020;395(10223):497-506.

4. Li JO, Lam DSC, Chen Y, Ting DSW. Novel Coronavirus disease 2019 (COVID-19): The importance of recognising possible early ocular manifestation and using protective eyewear. $\mathrm{Br} \mathrm{J}$ Ophthalmol 2020;104(3):297-298.

5. Mungmungpuntipantip R, Wiwanitkit V. Ocular manifestation, eye protection, and COVID-19. Graefes Arch Clin Exp Ophthalmol 2020;258(6):1339.

6. Wan Y, Shang J, Graham R, Baric RS, Li F. Receptor Recognition by the Novel Coronavirus from Wuhan: an Analysis Based on Decade-Long Structural Studies of SARS Coronavirus. J Virol 2020;94(7).

7. Hamming I, Timens W, Bulthuis ML, Lely AT, Navis G, van Goor H. Tissue distribution of ACE2 protein, the functional receptor for SARS coronavirus. A first step in understanding SARS pathogenesis. $J$ Pathol 2004;203(2):631-7. 
8. Chamsi-Pasha MA, Shao Z, Tang WH. Angiotensin-converting enzyme 2 as a therapeutic target for heart failure. Curr Heart Fail Rep 2014;11(1):58-63.

9. Choudhary R, Kapoor MS, Singh A, Bodakhe SH. Therapeutic targets of renin-angiotensin system in ocular disorders. J Curr Ophthalmol 2017;29(1):7-16.

10. Zhou Z, Kang H, Li S, Zhao X. Understanding the neurotropic characteristics of SARS-CoV-2: from neurological manifestations of COVID-19 to potential neurotropic mechanisms. J Neurol 2020;267(8):2179-2184.

11. Abrishami M, Tohidinezhad F, Daneshvar R, et al. Ocular Manifestations of Hospitalized Patients with COVID-19 in Northeast of Iran. Ocul Immunol Inflamm 2020;28(5):739-744.

12. Marinho PM, Marcos AAA, Romano AC, Nascimento $H$, Belfort $R$, Jr. Retinal findings in patients with COVID-19. Lancet 2020;395(10237):1610.

13. Vavvas DG, Sarraf D, Sadda SR, et al. Concerns about the interpretation of OCT and fundus findings in COVID-19 patients in recent Lancet publication. Eye (Lond) 2020.

14. Casagrande M, Fitzek A, Puschel K, et al. Detection of SARS-CoV-2 in Human Retinal Biopsies of Deceased COVID-19 Patients. Ocul Immunol Inflamm 20201-5.

15. Burgos-Blasco B, Guemes-Villahoz N, Donate-Lopez J, Vidal-Villegas B, Garcia-Feijoo J. Optic nerve analysis in COVID-19 patients. J Med Virol 2020.

16. Su XW, Palka SV, Rao RR, Chen FS, Brackney CR, Cambi F. SARS-CoV-2-associated Guillain-Barre syndrome with dysautonomia. Muscle Nerve 2020;62(2):E48-E49.

17. Fernandez-Dominguez J, Ameijide-Sanluis E, Garcia-Cabo C, Garcia-Rodriguez R, Mateos V. MillerFisher-like syndrome related to SARS-CoV-2 infection (COVID 19). J Neurol 2020;267(9):2495-2496.

18. DosSantos MF, Devalle S, Aran V, et al. Neuromechanisms of SARS-CoV-2: A Review. Front Neuroanat 2020;1437.

19. Seah I, Agrawal R. Can the Coronavirus Disease 2019 (COVID-19) Affect the Eyes? A Review of Coronaviruses and Ocular Implications in Humans and Animals. Ocul Immunol Inflamm 2020;28(3):391-395.

20. Ma ZW, Qiu WH, Zhou DN, Yang WH, Pan XF, Chen H. Changes in vessel density of the patients with narrow antenior chamber after an acute intraocular pressure elevation observed by OCT angiography. BMC Ophthalmol 2019;19(1):132.

21. Lommatzsch C, Rothaus K, Koch JM, Heinz C, Grisanti S. Vessel density in OCT angiography permits differentiation between normal and glaucomatous optic nerve heads. Int $\mathrm{J}$ Ophthalmol 2018;11(5):835-843.

22. van de Kreeke JA, Nguyen HT, Konijnenberg E, et al. Optical coherence tomography angiography in preclinical Alzheimer's disease. Br J Ophthalmol 2020;104(2):157-161.

23. Pellegrini M, Vagge A, Ferro Desideri LF, et al. Optical Coherence Tomography Angiography in Neurodegenerative Disorders. J Clin Med 2020;9(6). 
24. Criscuolo C, Cennamo G, Montorio D, et al. Assessment of retinal vascular network in amnestic mild cognitive impairment by optical coherence tomography angiography. PLoS One 2020;15(6):e0233975.

\section{Tables}

Table 1: Comparison of optic nerve head parameters and age of COVID-19 patients eyes versus normal eyes.

\begin{tabular}{|c|c|c|c|}
\hline & $\begin{array}{l}\text { Normal Eyes } \\
\text { Mean } \pm \text { SD } \\
\text { (Range) } \\
22 \text { Normal Healthy } \\
\text { Controls }\end{array}$ & $\begin{array}{l}\text { COVID-19 Patients } \\
\text { Eyes } \\
\text { Mean } \pm \text { SD } \\
\text { (Range) } \\
25 \text { Recovered } \\
\text { Patients }\end{array}$ & $\begin{array}{l}\text { P Value (Compare To } \\
\text { Normal) }\end{array}$ \\
\hline Age & $\begin{array}{l}41.5 \pm 10.5 \\
(24-53)\end{array}$ & $\begin{array}{l}36.7 \pm 7.3 \\
(25-61)\end{array}$ & 0.086 \\
\hline Cup/Disc Area Ratio & $\begin{array}{l}0.14 \pm 0.09 \\
(0-0.33)\end{array}$ & $\begin{array}{l}0.12 \pm 0.10 \\
(0-0.35)\end{array}$ & 0.415 \\
\hline $\begin{array}{l}\text { Cup/Disc Vertical } \\
\text { Ratio }\end{array}$ & $\begin{array}{l}0.37 \pm 0.18 \\
(0-0.60)\end{array}$ & $\begin{array}{l}0.30 \pm 0.21 \\
(0-0.61)\end{array}$ & 0.283 \\
\hline $\begin{array}{l}\text { Cup/Disc Horizontal } \\
\text { Ratio }\end{array}$ & $\begin{array}{l}0.32 \pm 0.16 \\
(0-0.55)\end{array}$ & $\begin{array}{l}0.27 \pm 0.19 \\
(0-0.59)\end{array}$ & 0.356 \\
\hline Rim Area & $\begin{array}{l}1.67 \pm 0.27 \\
(1.18-2.29)\end{array}$ & $\begin{array}{l}1.58 \pm 0.32 \\
(1.09-2.40)\end{array}$ & 0.313 \\
\hline Disc Area & $\begin{array}{l}1.97 \pm 0.31 \\
(1.47-2.74)\end{array}$ & $\begin{array}{l}1.81 \pm 0.30 \\
(1.22-2.40)\end{array}$ & 0.076 \\
\hline Cup Volume & $\begin{array}{l}0.09 \pm 0.18 \\
(0-0.87)\end{array}$ & $\begin{array}{l}0.06 \pm 0.08 \\
(0-0.34)\end{array}$ & 0.469 \\
\hline Peripapillary RNFL & $\begin{array}{l}108 \pm 10.77 \\
(101-129)\end{array}$ & $\begin{array}{l}112.04 \pm 7.69 \\
(83-133)\end{array}$ & 0.151 \\
\hline
\end{tabular}

RNFL: retinal nerve fiber layer; COVID-19: Coronavirus Disease 2019; SD: Standard Deviation 
Table 2: Comparison of small vessels (SV) vessel density (VD) of COVID-19 patients eyes versus normal eyes 


\begin{tabular}{|c|c|c|c|}
\hline & $\begin{array}{l}\text { Normal Eyes } \\
\text { Mean } \pm \text { SD } \\
\text { (Range) }\end{array}$ & $\begin{array}{l}\text { COVID-19 Patients Eyes } \\
\text { Mean } \pm \text { SD } \\
\text { (Range) }\end{array}$ & P Value \\
\hline Whole Image- SV VD & $\begin{array}{l}49.31 \pm 1.93 \\
(44.90-53.40)\end{array}$ & $\begin{array}{l}49.94 \pm 2.22 \\
(44.50-53.20)\end{array}$ & 0.308 \\
\hline Inside Disc- SV VD & $\begin{array}{l}49.43 \pm 4.96 \\
(37.70-56.40)\end{array}$ & $\begin{array}{l}45.46 \pm 6.22 \\
(24.80-53)\end{array}$ & 0.021 \\
\hline Whole PeriPapillary- SV VD & $\begin{array}{l}51.76 \pm 1.92 \\
(47-55.20)\end{array}$ & $\begin{array}{l}53.14 \pm 2.31 \\
(46-56.70)\end{array}$ & 0.032 \\
\hline PeriPapillary Superior Hemi- SV VD & $\begin{array}{l}52.01 \pm 2.16 \\
(46.90-55.70)\end{array}$ & $\begin{array}{l}53.12 \pm 2.90 \\
(44.40-57.10)\end{array}$ & 0.148 \\
\hline PeriPapillary Inferior Hemi - SV VD & $\begin{array}{l}51.79 \pm 3.31 \\
(44.90-62)\end{array}$ & $\begin{array}{l}53.16 \pm 2.13 \\
(47.70-57.90)\end{array}$ & 0.095 \\
\hline PeriPapillary Nasal Superior SV VD & $\begin{array}{l}49.37 \pm 2.96 \\
(42.40-53.70)\end{array}$ & $\begin{array}{l}49.99 \pm 3.84 \\
(37.90-56.10)\end{array}$ & 0.547 \\
\hline PeriPapillary Nasal Inferior SV VD & $\begin{array}{l}48.20 \pm 4.63 \\
(39-57.90)\end{array}$ & $\begin{array}{l}49.52 \pm 4.71 \\
(38-64.50)\end{array}$ & 0.337 \\
\hline PeriPapillary Inferior Nasal SV VD & $\begin{array}{l}48.54 \pm 2.94 \\
(42.30-52.90)\end{array}$ & $\begin{array}{l}53.21 \pm 4.12 \\
(45.40-59.50)\end{array}$ & $<0.001$ \\
\hline PeriPapillary Inferior Temporal SV VD & $\begin{array}{l}56.93 \pm 3.14 \\
(46.60-61.50)\end{array}$ & $\begin{array}{l}59.78 \pm 3.25 \\
(53.60-65.20)\end{array}$ & 0.004 \\
\hline PeriPapillary Temporal Inferior SV VD & $\begin{array}{l}52.15 \pm 3.57 \\
(47.30-60.40)\end{array}$ & $\begin{array}{l}53.69 \pm 3 \\
(45.40-58.20)\end{array}$ & 0.632 \\
\hline PeriPapillary Temporal Superior SV VD & $\begin{array}{l}55.86 \pm 4.02 \\
(44.20-61.30)\end{array}$ & $\begin{array}{l}55.96 \pm 4.50 \\
(44.50-63.80)\end{array}$ & 0.889 \\
\hline PeriPapillary Superior Temporal SV VD & $\begin{array}{l}55.24 \pm 2.76 \\
(50.50-60.20)\end{array}$ & $\begin{array}{l}57.0 \pm 3.92 \\
(49.50-63.30)\end{array}$ & 0.087 \\
\hline PeriPapillary Superior Nasal SV VD & $\begin{array}{l}49.03 \pm 3.39 \\
43.60-55.50)\end{array}$ & $\begin{array}{l}51.14 \pm 3.72 \\
(41.20-58.70)\end{array}$ & 0.049 \\
\hline
\end{tabular}


SV: small vessels; VD: vessel density; SD: Standard Deviation; COVID-19: Coronavirus Disease 2019

Table 3: Comparison of all vessels (AV), including both small and large vessels, vessel density (VD) of COVID-19 patients eyes versus normal eyes. 


\begin{tabular}{|c|c|c|c|}
\hline & $\begin{array}{l}\text { Normal Eyes } \\
\text { Mean } \pm \text { SD } \\
\text { (Range) }\end{array}$ & $\begin{array}{l}\text { COVID-19 Patients Eyes } \\
\text { Mean } \pm \text { SD } \\
\text { (Range) }\end{array}$ & P Value \\
\hline Whole Image - AV VD & $\begin{array}{l}56.08 \pm 1.89 \\
(52.50-60.20)\end{array}$ & $\begin{array}{l}56.44 \pm 2.29 \\
(51.40-59.10)\end{array}$ & 0.566 \\
\hline Inside Disc - AV VD & $\begin{array}{l}56.05 \pm 4.14 \\
(49.50-63.90)\end{array}$ & $\begin{array}{l}57.25 \pm 5.46 \\
(40.40-63.80)\end{array}$ & 0.057 \\
\hline Whole Peripapillary - AV VD & $\begin{array}{l}58.31 \pm 1.65 \\
(55-61.80)\end{array}$ & $\begin{array}{l}59.33 \pm 2.34 \\
(52.90-62.60)\end{array}$ & 0.110 \\
\hline Peripapillary Superior Half - AV VD & $\begin{array}{l}58.75 \pm 1.64 \\
(56.10-61.50)\end{array}$ & $\begin{array}{l}59.50 \pm 2.63 \\
(52-63.70)\end{array}$ & 0.257 \\
\hline Peripapillary Inferior Half - AV VD & $\begin{array}{l}57.90 \pm 2.08 \\
(53.20-62.60)\end{array}$ & $\begin{array}{l}59.11 \pm 2.30 \\
(53.90-63.60)\end{array}$ & 0.066 \\
\hline Grid Based AV VD Supero temporal & $\begin{array}{l}57.63 \pm 4.21 \\
(43.30-63.10)\end{array}$ & $\begin{array}{l}59.14 \pm 3.02 \\
(52.60-64)\end{array}$ & 0.161 \\
\hline Grid Based AV VD Temporal & $\begin{array}{c}56.46 \pm 3.08 \\
(46.60-62)\end{array}$ & $\begin{array}{l}57.01 \pm 3.37 \\
(50.40-61.50)\end{array}$ & 0.565 \\
\hline Grid Based AV VD Infero temporal & $\begin{array}{l}58.49 \pm 4.47 \\
(42.60-64.40)\end{array}$ & $\begin{array}{l}58.67 \pm 3.43 \\
(49.20-64.10)\end{array}$ & 0.879 \\
\hline Grid Based AV VD Superior & $\begin{array}{l}56.85 \pm 2.77 \\
(52.50-62.10)\end{array}$ & $\begin{array}{l}58.68 \pm 3.36 \\
(50.80-63.40)\end{array}$ & 0.051 \\
\hline Grid Based AV VD Central & $\begin{array}{l}58.10 \pm 4.56 \\
(50-64.60)\end{array}$ & $\begin{array}{l}60.35 \pm 3.23 \\
(49-64.40)\end{array}$ & 0.061 \\
\hline Grid Based AV VD Inferior & $\begin{array}{l}60.68 \pm 2.14 \\
(55.30-64.50)\end{array}$ & $\begin{array}{l}62.56 \pm 3.15 \\
(54.10-66.90)\end{array}$ & 0.023 \\
\hline Grid Based AV VD Supero nasal & $\begin{array}{l}51.71 \pm 4.19 \\
(43.90-58.20)\end{array}$ & $\begin{array}{l}52.09 \pm 3.36 \\
(43.60-59.90)\end{array}$ & 0.739 \\
\hline Grid Based AV VD Nasal & $\begin{array}{l}52.30 \pm 5.48 \\
(43.80-67.90)\end{array}$ & $\begin{array}{l}52.52 \pm 3.50 \\
(44.60-62.40)\end{array}$ & 0.869 \\
\hline Grid Based AV VD Inferonasal & $\begin{array}{r}50.29 \pm 3.91 \\
\text { Page } 14 / 15\end{array}$ & $50.35 \pm 3.84$ & 0.903 \\
\hline
\end{tabular}




$$
(44.40-59.80) \quad(41.60-58.10)
$$

AV: all vessels; VD: vessel density; SD: Standard Deviation; COVID-19: Coronavirus Disease 2019

\section{Figures}

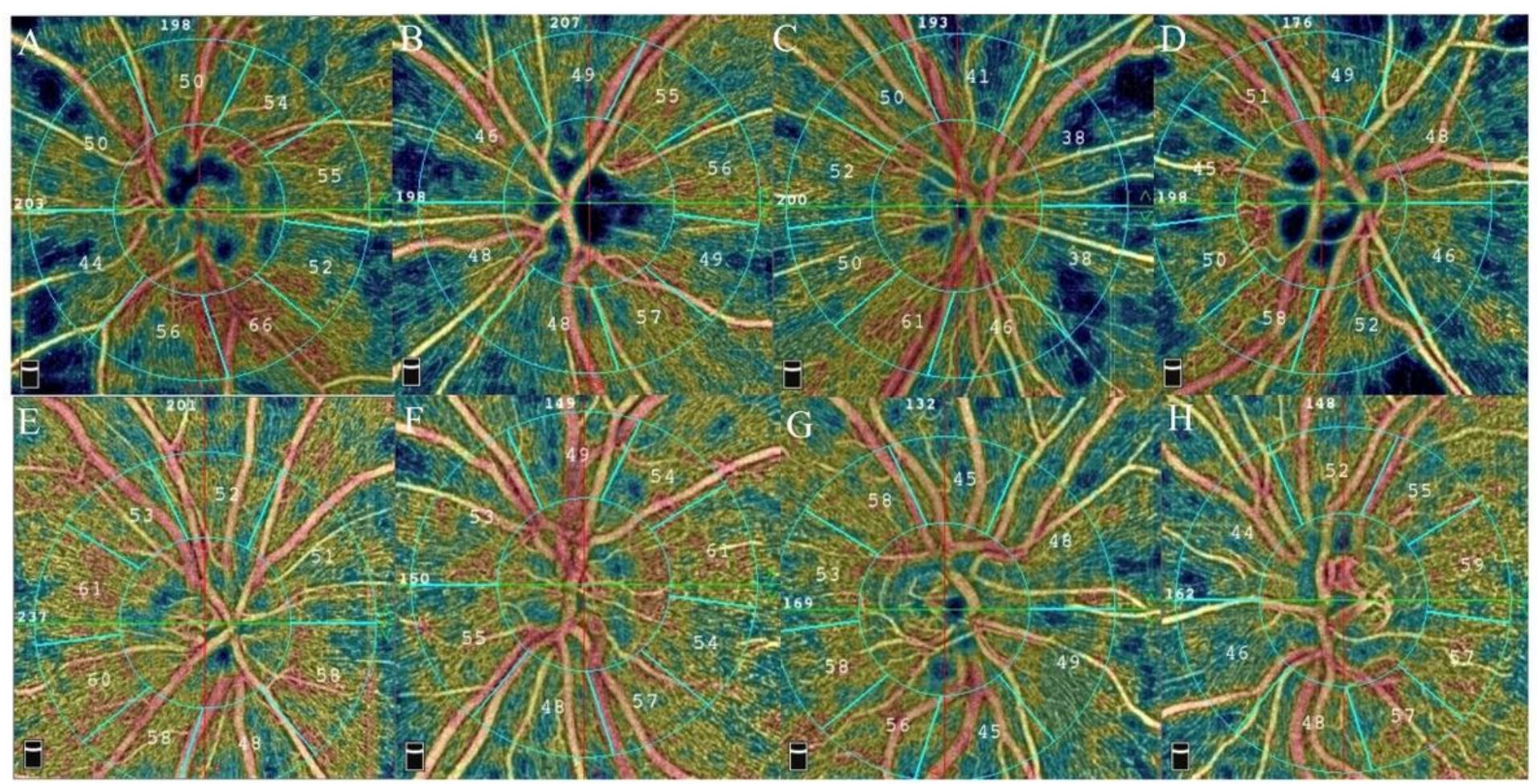

\section{Figure 1}

En-face optical coherence tomography angiograms (OCTA) segmented at the level of the radial peripapillary capillary (RPC) network from 4 recovered COVID-19 patients (A-D) versus 4 age matched normal controls $(\mathrm{E}-\mathrm{H})$. Note the remarkable flow deficits present in the en-face angiograms from the COVID cases. 